\title{
1 Ether lipid and sphingolipid expression patterns are G-protein coupled 2 estrogen receptor 1-dependently altered in breast cancer cells
}

3 Lisa Hahnefeld ${ }^{1}$, Lisa Gruber $^{1}$, Nina Schömel ${ }^{1}$, Caroline Fischer $^{1}$, Peter Mattjus ${ }^{2}$, Robert

4 Gurke $^{1,3}$, Martina Beretta $^{4}$, Nerea Ferreirós ${ }^{1}$, Gerd Geisslinger $^{1,3}$, Marthe-Susanna Wegner ${ }^{1,4}$

$5{ }^{1}$ pharmazentrum frankfurt/ZAFES, Institute of Clinical Pharmacology, Johann Wolfgang 6 Goethe University, Theodor Stern-Kai 7, 60590 Frankfurt am Main, Germany.

$72{ }^{2}$ Åbo Akademi University, Biochemistry, Faculty of Science and Engineering Artillerigatan 6A, 8 III, BioCity FI-20520 Turku, Finland.

$9{ }^{3}$ Fraunhofer Institute for Molecular Biology and Applied Ecology IME, Branch for 10 Translational Medicine and Pharmacology TMP, Theodor Stern-Kai 7, 60590 Frankfurt am 11 Main, Germany.

$12{ }^{4}$ School of Biotechnology and Biomolecular Sciences, University of New South Wales, 13 Sydney, New South Wales 2052, Australia.

Corresponding author:

25 School of Biotechnology \& Biomolecular Sciences

27 Phone: +61 (2) 93856516 
E-Mail: wegner@med.uni-frankfurt.de

\section{Abstract}

Identifying co-expression of lipid species is challenging, but indispensable to identify novel therapeutic targets for breast cancer treatment. Lipid metabolism is often dysregulated in cancer cells, and changes in lipid metabolism affect cellular processes such as proliferation, autophagy, and tumor development. In addition to mRNA analysis of sphingolipid metabolizing enzymes, we performed liquid chromatography time-of-flight mass spectrometry analysis in three breast cancer cell lines. These breast cancer cell lines differ in estrogen receptor and G-protein coupled estrogen receptor 1 status. Our data show that sphingolipids and non-sphingolipids are strongly increased in $\mathrm{SKBr} 3$ cells. SKBr3 cells are estrogen receptor negative and G-protein coupled estrogen receptor 1 positive. Treatment with G15, a G-protein coupled estrogen receptor 1 antagonist, abolishes the effect of increased sphingolipid and non-sphingolipid levels in SKBr3 cells. In particular, ether lipids are expressed at much higher levels in cancer compared to normal cells and are strongly increased in SKBr3 cells. Our analysis reveals that this is accompanied by increased sphingolipid levels such as ceramide, sphingadiene-ceramide and sphingomyelin. This shows

44 the importance of focusing on more than one lipid class when investigating molecular 45 mechanisms in breast cancer cells. Our analysis allows unbiased screening for different lipid classes leading to identification of co-expression patterns of lipids in the context of breast cancer. Co-expression of different lipid classes could influence tumorigenic potential of breast cancer cells. Identification of co-regulated lipid species is important to achieve improved breast cancer treatment outcome.

50 


\section{Keywords}

58 sphingolipids, ether lipids, GPER1, AGMO, AGPS

\section{Highlights}

60

- LC-HRMS analysis allows identification of co-expression between lipid classes

- Putative co-expression of sphingolipid and non-sphingolipid classes

- Ether lipids are strongly upregulated in SKBr3 cells (ER negative, GPER1 positive)

\section{Introduction}

Breast cancer is the most common cancer among females in North America, Europe and Oceania and shares the lead with cervical cancers in South America, Africa and most of Asia (reviewed in (Torre et al., 2016)). 70 to $78 \%$ of the breast tumors express the transcriptionally more active estrogen receptor (ER) subtype $\alpha$, which is declared as an ER positive (+) status (Pujol et al., 1994, Chu and Anderson, 2002). ER + tumor proliferation is hormone driven. Current therapies are based on either lowering patient estrogen levels by aromatase inhibition or by blocking estrogen-mediated signaling pathways through selective ER modulator (SERM) or selective ER downregulator (SERD) treatment. Normally, following diffusion into the cell, estrogen mediates its function by binding on ERs, which leads to translocation of the receptor into the nucleus. This results in activation of manifold signaling pathways by gene transcription alteration. Membrane-associated ERs also include G-protein coupled estrogen receptor 1 (GPER1). GPER1 mediates rapid non-genomic as well as indirect genomic responses (reviewed in (Hsu et al., 2019)). This membrane-associated ER is involved in physiological processes such as cell growth and pathophysiological processes such as tumor development (reviewed in (Olde and Leeb-Lundberg, 2009, Wang et al., 2010)) and is discussed controversially in the literature. For example, it is still unclear where exactly GPER1 is subcellularly located and whether this receptor contributes to tumorigenic potential, or indicates less aggressiveness of breast cancer cells.

It has been shown that abnormalities of lipids influence cellular processes resulting in metabolic disorders or tumor development (reviewed in (Long et al., 2018, Pakiet et al., 2019)). Thereby, the influence of lipids ranges from promoting cancer to suppressing cancer 
85

86

(reviewed in (Lim, 2018)). It has been observed that ether lipids are expressed at much higher levels in cancer as compared to normal cells (reviewed in (Dean and Lodhi, 2018)). Also, plasma ether-linked phosphocholine (PC) species, which are elevated in breast cancer patients, can be used as a biomarker for the diagnosis of breast cancer (Chen et al., 2016). Furthermore, Benjamin et al. showed elevated ether lipid levels in more aggressive breast cancer cell lines such as 231 MFP (Benjamin et al., 2013). It has also been speculated that ether lipids seem to be capable of taking over the role of certain sphingolipids both in cells and organisms (reviewed in (Jimenez-Rojo and Riezman, 2019)). Furthermore, deregulated sphingolipid metabolism contributes to tumor development and progression (reviewed in (Ryland et al., 2011, Wegner et al., 2016)). Sphingolipids such as ceramide and sphingomyelin are significantly increased in human breast cancer (Nagahashi et al., 2016) compared to normal tissue (reviewed in (Furuya et al., 2011)). However, there is contradictory data relating to the involvement of lipid classes in cellular pathophysiological processes. One example is the finding that inhibition or silencing of acetyl-CoA carboxylase (ACC), which is essential for fatty acid synthesis, is shown to limit cancer cell growth (reviewed in (Lim, 2018)). Surprisingly, liver-specific ACC knockout leads to increased tumor incidence in a hepatocellular carcinogen diethylnitrosamine (DEN) mouse model (Nelson et al., 2017). This indicates that lipogenesis is not essential for liver tumorigenesis in the DEN mouse model. Another example is adipose triglyceride lipase (ATGL), which inhibits growth of several cancer cell types when suppressed, but mice lacking ATGL develop lung tumors (reviewed in (Chen and Huang, 2019)). Given the complexity of the influence that lipids have on tumor development, it is important to analyze biological samples by a method which allows an unbiased investigation of several species of lipids instead of focusing on a single lipid class.

Here, we investigated co-expression of different lipid species in breast cancer cells with differing ER and GPER1 status using liquid chromatography time-of-flight mass spectrometry (LC-HRMS). Our LC-HRMS analysis show co-regulation of sphingolipid and non-sphingolipid expression and indicate that tumorigenic potential of breast cancer cells is affected by this. Strikingly, ether lipids and sphingolipids are strongly increased in SKBr3 cells (ER negative, GPER1 positive). This GPER1-dependent co-regulation of sphingolipid and non-sphingolipid expression is a novel finding, which might contribute to the identification of novel therapeutic targets in breast cancer therapy. 

breast cancer cells

120 First we analyzed estrogen receptor (ER) and G-protein coupled estrogen receptor 1 (GPER1)

121 mRNA expression status of T47D, MCF-7 and SKBr3 cells by quantitative RealTime (qRT)-PCR.

122 T47D cells only express ER $\alpha$ resulting in an ER + and GPER1 - status (Figure 1A). MCF-7 cells

123 are ER $\alpha, E R \beta$ and GPER1 expressing breast cancer cells. Accordingly, MCF-7 cells are

124 identified to exhibit an ER + and GPER1 + status. GPER1 mRNA expression is the highest in

125 SKBr3 cells as compared to the other cell lines showing a GPER1 + status, whereas ER $\alpha$ and

$126 \mathrm{ER} \beta$ are rarely detectable. Therefore, SKBr3 cells are an ER - status breast cancer cell line.

127 Relative mRNA expression below the value of 200 is assumed to be a negative status for the 128 respective gene. The results displayed in Figure $\mathbf{1 A}$ are in line with other studies (Mota et al., 129 2017, Deng et al., 2020). 


\subsection{Basal mRNA expression of sphingolipid metabolizing enzymes}

131 Next we determined the basal mRNA expression of several anabolic and catabolic 132 sphingolipid metabolizing enzymes in T47D, MCF-7 and SKBr3 cells. In general, 133 sphingomyelin synthase 2 (SMS2), ceramide kinase (CERK), UDP-glucose ceramide 134 glucosyltransferase (UGCG), acid ceramidase (aCDase) and neutral sphingomyelinase 1 135 (nSMase 1) are the most highly expressed genes in all three breast cancer cell lines (Figure 136 1B and C). Exceptions are SPHK1 and GalCerS, which are highly expressed in SKBr3, but not 137 T47D and MCF-7 cells (Figure 1B). Compared to MCF-7 and SKBr3 cells, T47D cells express 138 higher amounts of UGCG (Figure 1B). MCF-7 cells as compared to the other cell lines exhibit 139 a strong mRNA expression of the anabolic enzymes ceramide synthase 2 and 6 (CerS2 and 140 CerS6) (Figure 1B). Notably, UGCG mRNA expression is comparable to CerS2 and CerS6 mRNA expression in MCF-7 cells and SMS2 is the most highly expressed gene in MCF-7 cells

142 (Figure 1B). The catabolic enzymes aCDase and nSMase 1 are also highly expressed in MCF-7 143 cells when compared to the other cell lines (Figure 1C). Since MCF-7 cells express ER subtypes $\alpha$ and $\beta$ and GPER1 these enzymes could potentially be regulated by ER $\alpha, \beta$ and GPER1. Interestingly, ceramide synthase 4 (CerS4), sphingosine kinase 1 (SPHK1), CERK and galactosylceramide synthase (GalCerS) are strongly expressed in GPER1 + SKBr3 cells compared to the other cell lines (Figure 1B). The data reveal differing expression patterns of sphingolipid metabolizing enzymes in breast cancer cells exhibiting unequal ER and GPER1 status.

\subsection{ER- and GPER1-dependent sphingolipid levels}

151

152

153

154

155

156

157

158

159

160

In order to screen for ER-dependent changes on sphingolipid levels we performed LC-HRMS analysis. ER - SKBr3 cells exhibit significantly reduced dihydroceramide (dhCer) levels compared to MCF-7 cells (Figure 2A and supplemental data $\mathbf{1 A}$ ), whereas ceramide levels are strongly increased (Figure 2B and supplemental data 1A). Sphingadiene-ceramide concentration is also strongly increased in SKBr3 cells compared to ER + cells, albeit MCF-7 cells exhibit a higher sphingadiene-ceramide concentration than T47D cells (Figure 2C and supplemental data 1A). Galactosylceramide (GalCer)/glucosylceramide (GlcCer) levels in SKBr3 cells are increased compared to MCF-7 cells, whereas no significant differences between MCF-7 and T47D cells were detected (Figure 2D and supplemental data 1B). Lactosylceramide (LacCer) concentration in T47D cells is the lowest compared to MCF-7 and 
$161 \mathrm{SKBr} 3$ cells (Figure 2E and supplemental data 1B). Additionally, sphingomyelin (SM)

162

163

164

165

166

167

168

169

170

171

172

173

174

175

176

177

178

179

180

181

182

183

184

185

186

187

188

189

190

191

concentration appears to follow the expression of GPER1-mRNA with highest level in SKBr3 cells and significantly lowest level in T47D cells (Figure 2F and supplemental data 1C). Treatment with G15, a GPER1 antagonist, significantly reduced ceramide and sphingadieneceramide level in SKBr3 cells. Dihydroceramide, ceramide, GalCer/GlcCer, LacCer and sphingomyelin levels are significantly increased in MCF-7 cells (supplemental data 1D). No effect of G15 treatment on the analyzed lipid levels in T47D (GPER1 -) could be detected (supplemental data 1D and $2 \mathrm{H}$ ). In summary, sphingolipid analysis revealed that the high anabolic enzyme mRNA expression in SKBr3 cells is reflected on sphingolipid levels by high ceramide, sphingadiene-ceramide, GalCer/GlcCer and SM levels. Furthermore, the G15 treatment data indicate that sphingolipid levels are GPER1-dependently regulated.

\subsection{ER- and GPER1-dependent non-sphingolipid levels}

LC-HRMS analysis revealed GPER1- and ER-dependent alterations of non-sphingolipid levels. Cholesterol levels are the lowest in T47D and the highest in SKBr3 cells (Figure 3A). Total sterol ester concentration is the lowest in MCF-7 cells and the highest in SKBr3 cells (Figure 3B and supplemental data 2A). By far the most altered lipid concentration between the three cell lines is the ether lipid concentration. SKBr3 cells exhibit a 140-fold increased ether lipid level compared to ER + cell lines (Figure 3C and supplemental data 2B). Diglycerides (DG) follow the same trend as cholesterol with T47D cells having the lowest and SKBr3 cells the highest concentration (Figure 3D and supplemental data 2C). In contrast, triglyceride (TG) content is low in MCF-7 cells as compared to T47D and SKBr3 cells (Figure 3E and supplemental data 2D). Glycerophospholipids appear most abundant in MCF-7 cells (Figure 3F and supplemental data 2E), whereas lyso-glycerophospholipids are the lowest in MCF-7 cells (Figure 3G and supplemental data 2F). Lyso-glycerophospholipids are statistically increased in SKBr3 cells as compared to T47D cells (Figure 3G and supplemental data 2F). Acylcarnitine levels are significantly decreased in SKBr3 cells compared to MCF-7 cells, whereas no difference compared to T47D cells could be detected (Figure $\mathbf{3 H}$ and supplemental data 2G). Treatment with the GPER1 antagonist G15 leads to significantly reduced levels of sterol ester and ether lipids in $\mathrm{SKBr} 3$ cells (supplemental data $\mathbf{2 H}$ ). In contrast, G15 stimulation leads to significantly increased levels of cholesterol, diglyceride, glycerophospholipids and acylcarnitines (supplemental data $2 \mathrm{H}$ ). SKBr3 cells exhibit 
192 increased sphingolipid levels as compared to the other cell lines, as well as increased levels 193 of several non-sphingolipids such as cholesterol, DGs and ether lipids. This indicates that 194 sphingolipid and non-sphingolipid pathways might be co-regulated in SKBr3 cells. In addition, 195 treatment with the GPER1 antagonist G15 indicate GPER1-dependent co-regulation of sphingolipids and non-sphingolipids in GPER1 + breast cancer cells.

\subsection{Effect of ER and GPER1 on cell proliferation}

198

199

200

201

202

203

204

205

206

207

208

209

210

211

212

213

214

215

216

217

218

219

220

221

222

There are differences in morphology between the three cell lines such that T47D cells are the smallest in size, MCF-7 cells are larger and SKBr3 cells are the largest (Figure 4A). The results of the proliferation assay show that MCF-7 cells proliferate faster than SKBr3 cells, which in turn proliferate faster than T47D cells (Figure 4B). Since the three breast cancer cell lines differ in their ER and GPER1 status and in their sphingolipid and non-sphingolipid expression pattern, it is possible that cell size and proliferation is affected by this.

\subsection{GPER1-dependent ether lipid metabolizing enzymes mRNA expression}

Since a strong GPER1-dependent increase of ether lipid level could be detected, we analyzed several enzymes involved in the ether lipid metabolism on mRNA level by qRT-PCR. Glyceronephosphate O-acyltransferase (GNPAT) is a crucial enzyme in ether lipid synthesis and is significantly lowered in MCF-7 cells compared to the other two cell lines (Figure 4C). Another key enzyme in ether lipid synthesis is alkylglycerone phosphate synthase (AGPS). AGPS is highly increased in $\mathrm{SKBr} 3$ cells, which fits the finding of strongly increased ether lipid concentrations in SKBr3 cells (Figure 4C). The alkylglycerol monooxygenase (AGMO) cleaves the O-alkyl bond of ether lipids leading to ether lipid degradation. Surprisingly, SKBr3 cells, which exhibit a high amount of ether lipids, also show strongly increased AGMO mRNA expression (Figure 4C). This might indicate a GPER1-dependent mRNA expression regulation of AGMO. In addition, fatty acid desaturase 1 (FADS1) mRNA expression is strongly increased in $\mathrm{SKBr} 3$ cells (Figure 4C). Carnitine palmitoyltransferase 1A (CPT1A) mRNA expression in $\mathrm{SKBr} 3$ cells is significantly reduced compared to MCF-7 cells, whereas no difference could be detected as compared to T47D, which verifies the LC-HRMS analysis results for acylcarnitine levels (Figure 4C). When normalizing LC-HRMS analysis results using median peak ratio (MPR) as compared to one internal standard (IS) per lipid class, the distribution of the reading points does not change (Figure 5 and supplemental data 3), whereby effects ascribable to cell size are excluded. In summary, our data indicate high ether lipid turnover 
223 in GPER1 +, but ER - cells (SKBr3) and a putative GPER1-dependent regulation of the

224 metabolizing enzymes.

225

226

227

228

229

230

231

232

233

234

235

236

237

238

239

240

241

242

243

244

245

246

247

\section{Materials and Methods}

\subsection{Cell lines}

MCF-7, T47D and SKBr3 cells were purchased from the Health Protection Agency (European Collection of Cell Cultures, ECACC, Salisbury, UK) and were cultured in phenol-red free Dulbecco's Modified Eagle's Medium (DMEM) supplemented with 5 \% charcoaled fetal bovine serum (FBS), 1 \% sodium pyruvate and $1 \%$ GlutaMAX. They were maintained in a humidified, $5 \% \mathrm{CO}_{2}$ supplied atmosphere incubator at $37^{\circ} \mathrm{C}$.

\subsection{Quantitative real-time-PCR (qRT-PCR)}

Total RNA was isolated using RNeasy Mini Kit (QIAGEN, Hilden, Germany). cDNA was synthesized from $300 \mathrm{ng}$ total RNA using VERSO ${ }^{\text {TM }}$ CDNA Synthesis Kit (Thermo Fisher Scientific, ABgene, Epsom, UK). Gene specific PCR products were assayed using Maxima EvaGreen qPCR Master Mix on a 7500fast quantitative PCR system (TaqMan ${ }^{\circledR}$, Life Technologies, Darmstadt, Germany). Relative gene expression was determined using the $\triangle C T$ method, normalizing relative values to the expression level of $60 \mathrm{~S}$ ribosomal protein $\mathrm{L37a}$ (RPL37A) as a housekeeping gene. It is shown that RPL37A is the optimal single reference gene when normalizing gene expression in meningiomas and control tissue (Pfister et al., 2011). Furthermore, Maltseva et al. showed that RPL37A has similar high expression stability values compared to the other genes such as ACTB or RPS23 in breast cancer cells (Maltseva et al., 2013). Accordingly, RPL37A is a suitable housekeeper gene for our study. The primer mix for sphingomyelin synthase 1 und 2 (SMS1 and SMS2) and galactosylceramide synthase (GalCerS) detection were purchased from GeneCopeia (Rockville, USA) and the GPER1primermix from Realtimeprimers (Pennsylvania, USA).

Table 1 qRT-PCR primer sequences.

\begin{tabular}{|c|c|c|}
\hline \multirow[t]{2}{*}{ Gene } & \multicolumn{2}{|c|}{ Sequence $\left(5^{\prime} \rightarrow 3^{\prime}\right)$} \\
\hline & Forward primer & Reverse primer \\
\hline RPL37A & ATT GAA ATC AGC CAG CAC GC & AGG AAC CAC AGT GCC AGA TCC \\
\hline CerS2 & CCA GGT AGA GCG TTG GTT & CCA GGG TTT ATC CAC AAT GAC \\
\hline CerS4 & CTG GTG GTA CCT CTT GGA GC & CGT CGC ACA CTT GCT GAT AC \\
\hline CerS5 & CAA GTA TCA GCG GCT CTG T & ATT ATC TCC CAA CTC TCA AAG A \\
\hline CerS6 & AAG CAA CTG CAG TGG GAT GTT & AAT CTG ACT CCG TAG GTA AAT ACA \\
\hline
\end{tabular}




\begin{tabular}{l|l|l}
\hline $\mathbf{E R \boldsymbol { \alpha }}$ & GGG AAG TAT GGC TAT GGA ATC TG & CTG GAG AGT AGC GAG TCT CC \\
\hline $\mathbf{E R \boldsymbol { \beta }}$ & AGC ACG GCT CCA TAT ACA TAC C & TGG CTG GAT ATT CAT GGT GGC \\
\hline SPHK1 & GTC ACG TGC AGC CCC TTT & CGC GCG TGG TTC CG \\
\hline UGCG & TGC TCA GTA CAT TGC CGA AGA & TGG ACA TTG CAA ACC TCC AA \\
\hline CERK & TAA CCC CCA AAG TCA CAA AA & CAT CTC CAC CAA CACAGA CA \\
\hline aCDase & TGT GGA TAG GGT TCC TCA CTA GA & TTG TGT ATA CGG TCA GCT TGT TG \\
\hline aSMase & CCT GGA GAG CCT GTT GAG TG & GTT GGT CCT GACGAG TCT GG \\
\hline nSMase 1 & TTT GGT GTC CGC ATT GAC TA & TAG AGC TGG GGt TCT GCT GT \\
\hline nSMase 2 & CAA CAA GTG TAA CGA CGA TGC C & CGA TTC TTT GGT CCT GAG GTG T \\
\hline nSMase $\mathbf{3}$ & CAC CCA GGA TGA GAA TGG AAA & GTC CGT CCT CAC CCA CGA T \\
\hline AGMO & CTG ACC TTG ACT TCC ATT GGA TT & CAA GCA ACG GAG AGT TTC CAT A \\
\hline GNPAT & GCT GCT ACG AAT GTC GGG T & TGT CCC TTC GAG GAA AAA TTC AA \\
\hline AGPS & AGG GAA GGA ATG TTT GAG CGA & GCA GGA CAC ATC AGG CCAT \\
\hline FADS1 & CCA ACT GCT TCC GCA AAG AC & GCT GGT GGT TGT ACG GCA TA \\
\hline CPT1A & ATCAAT CGG ACT CTG GAA ACG G & TCA GGG AGT AGC GCA TGG T \\
\hline
\end{tabular}

\subsection{Lipidomics analysis}

\subsubsection{Materials}

250 Water, isopropanol, methanol (LC-MS grade) and methyl-tert-butyl-ether (MTBE, HPLCgrade) were purchased from Carl Roth (Karlsruhe, Germany). Ammonium formate (for mass spectrometry, $\geq 99.0 \%$ ) and Sulfinpyrazon (100 \%) were purchased from Sigma-Aldrich

253 (Munich, Germany) and acetonitrile (ULC-MS grade) from Biosolve B. V. (Valkenswaard, 254 Netherlands). APCl positive calibration solutions was obtained from Sciex (Darmstadt, 255 Germany) and formic acid (98-100 \%) from AppliChem (Darmstadt, Germany). All internal standards were purchased from Avanti Polar Lipids (Alabaster, AL, USA).

\subsubsection{Liquid chromatography time-of-flight mass spectrometry (LC-HRMS)}

258 Three experiments with three replicates each were performed. The sample processing and 259 LC-HRMS measurement was carried out as described previously (Hahnefeld et al., 2020). 260 Approximately $5 \times 10^{5}$ cells in $150 \mu \mathrm{L}$ PBS were thawed in the fridge for 30 min before 261 extraction with $150 \mu \mathrm{L}$ internal standards in methanol and $500 \mu \mathrm{L}$ MTBE. After centrifugation 262 at $20,000 \mathrm{~g}$ for $5 \mathrm{~min}$, the upper organic phase was transferred and the aqueous phase was reextracted using $200 \mu \mathrm{L}$ of MTBE: methanol: water (10:3:2.5, v/v/v). The combined organic

264 phases were split for measurement in positive and negative ionization mode, dried at $45{ }^{\circ} \mathrm{C}$ under a nitrogen stream and stored at $-20^{\circ} \mathrm{C}$ pending analysis. The samples were dissolved in $120 \mu \mathrm{L}$ methanol before analysis. For quality control, the different cell lines were pooled

267 with two injections at the beginning and the end of each run and one after every 10th 268 sample. The LC-MS measurement was carried out on a Shimadzu Nexera-X2 (Shimadzu Corporation, Kyoto, Japan) with a Zorbax RRHD Eclipse Plus C8 $1.8 \mu \mathrm{m}$ 50x2.1 mm ID column 
270 (Agilent, Waldbronn, Germany) coupled to TripleTOF 6600 (Sciex, Darmstadt, Germany) with 271 electrospray ionization operating in positive and negative ionization mode. A mass range

272 from 100 to $1000 \mathrm{~m} / \mathrm{z}$ was scanned together with data-dependent acquisition for improved 273 identification with a mass error of $\pm 5 \mathrm{ppm}$. The data acquisition was performed using 274 Analyst TF v1.71. Compound identification and semi-targeted analysis was achieved with 275 MasterView v1.1 and MultiQuant v3.02 software as described previously (Hahnefeld et al., 276 2020). The software was obtained from Sciex (Darmstadt, Germany).

277

278

279

280

281

282

283

284

285

286

287

288

289

290

291

292

293

294

295

296

297

298

299

\subsubsection{Sample Normalization}

LC-HRMS analysis results were compared after normalization once with one internal standard (IS) per lipid class and once with median peak ratio (MPR) as calculated by MarkerView v1.1 software. For MPR calculation a selected reference sample, usually the first QC sample, is used to generate a list of all peaks with a minimum peak area of $1 \%$ of the largest signal. For each peak in the list the peak area is divided by the peak area of the reference sample and subsequently the median of the area ratios is calculated. If no peak appears in the analyzed sample, the area ratio is set to the value 1 . Accordingly, a normalization factor for each sample was generated and the values of all analytes were multiplied by this normalization factor. The results normalized with one internal standard per lipid class were used for further analysis.

\subsection{Proliferation assay}

For quantitative proliferation assays, cells were seeded at a density of $5 \times 10^{4}$ cells/well of a 6-well plate (cell culture multiwell plate, 6 well, clear, sterile, (Greiner AG, Kremsmünster, Austria)). Since the cells were not $100 \%$ confluent following 5 days of culture, the media was not replenished during the 5 days of culture. Cells were harvested at day 1, 2, 3, 4, 5 and living cell number was counted using a Neubauer counting chamber and trypan blue (labels dead cells exclusively).

\subsection{Statistical analysis}

Data are presented as mean \pm standard error of the mean (SEM). Statistical analyses were performed with GraphPad Prism 7 software. Significant differences $(p<0.05)$ between groups were assessed by Tukey's multiple comparison test as indicated in the figure descriptions. 
300

301

302

303

304

305

306

307

308

309

310

311

312

313

314

315

316

317

318

319

320

321

322

323

324

325

326

327

328

329

330

331

\section{Discussion}

With our LC-HRMS analysis approach we were able to show co-expression of sphingolipids and non-sphingolipids in breast cancer cells. Importantly, GPER1 might be involved in regulating this co-expression of different lipid species.

Our analysis identified a distinct mRNA expression pattern in both anabolic and catabolic sphingolipid metabolizing enzymes among the three breast cancer cell lines tested. Low CerS5 and CerS6 mRNA expression (responsible for the production of C16 to C20 ceramides) in SKBr3 cells (GPER1 +, ER -) is in line with results we published previously showing decreased CerS5 and CerS6 mRNA (production of C16 ceramides) level in MCF-7 cells following stable GPER1 plasmid transfection (MCF-7/GPER1) (Wegner et al., 2019). However, following GPER1 overexpression in MCF-7 cells, CerS2 mRNA (production of C20-26 ceramides) level is increased and CerS4 mRNA level unchanged (Wegner et al., 2019), whereas SKBr3 cells exhibit lower CerS2 and higher CerS4 mRNA levels compared to MCF-7 wild type cells. This indicates that regulation of CerS2 and CerS4 is regulated by both GPER1 and $E R$ and that the lack of ER $\alpha$ and $\beta$ in $\mathrm{SKBr} 3$ cells contributes to the differences in $\mathrm{SKBr} 3$ and MCF-7/GPER1 cells. GPER1-dependent SPHK1 activity is shown (reviewed in (Sukocheva and Wadham, 2014)) and is in line with our data, which reveal high SPHK1 mRNA levels in GPER1 + cells (SKBr3). Sukocheva et al. have shown estrogen-dependent SPHK1 activation that leads to sphingosine 1-phosphate (S1P) release, accordingly to Edg-3 activation and results in enhanced growth factor receptor (EGFR) transactivation (Sukocheva et al., 2006).

Our previous data show that GPER1 regulates CerS transcription ligand-independently (Wegner et al., 2014). Also, since phenol-red is known to mediate estrogen-like mechanisms (Wesierska-Gadek et al., 2007), we used phenol-red free media and $5 \%$ charcoaled FBS in our current study. This could indicate that in addition to ligand-dependent mechanisms, ligand-independent mechanism mediated by ERs could also contribute to SPHK1 regulation. Since SPHK1 is a marker for poor prognosis in breast cancer patients (reviewed in (Sukocheva and Wadham, 2014)) it would be intriguing to investigate GPER1-dependent mechanisms of SPHK1 regulation. No distinct differences on SMS1 and SMS2 mRNA expression levels between the three cell lines were observed indicating that SMS are constitutively expressed. However, we detected SMS1 and SMS2 mRNA expression increase following stable GPER1 overexpression in MCF-7 cells (Wegner et al., 2019). This indicates a putative interaction of GPER1 and ER $\alpha$ and or $\beta$. Moro et al. showed suppression of CERK 
332 expression in cancer cells (Moro et al., 2018). The breast cancer cell line SKBr3 exhibits 333 strongly increased CERK mRNA expression. This indicates that high CERK expression might 334 not be a prognostic marker for cancer in general, but rather identifies a less aggressive type 335 of cancer. Interestingly, the product of CERK activity, ceramide 1-phosphate (C1P) is a known 336 inducer of inflammatory processes in cancer cells, which could contribute to the activation 337 of pro-cancerous signaling pathways (reviewed in (Dei Cas and Ghidoni, 2018, Arana et al., 338 2010)). Indeed, we measured increased FADS1 mRNA expression in SKBr3 cells. FADS1 339 catalyzes the final step in arachidonic acid synthesis. However, Owczarek et al. showed that 340 GalCerS, which is also highly expressed in SKBr3 cells, functions as a pro-tumorigenic protein 341 by inhibiting apoptosis (Owczarek et al., 2013). This is contradictory to the finding that SKBr3 342 cells are less aggressive, however, we have already shown that UGCG overexpression in 343 MCF-7 cells leads to increased glutamine uptake (Schomel et al., 2019). This results in 344 reinforced oxidative stress response and fueled tricarboxylic acid (TCA) cycle, which is 345 accompanied by increased cell proliferation (Schomel et al., 2019). Since MCF-7 cells exhibit 346 a p53 wildtype while T47D (Lim et al., 2009) and SKBr3 cells (Garufi et al., 2016) display a p53 347 mutant status and a high UGCG mRNA expression, it is likely that UGCG overexpression is 348 connected to p53 signaling pathway inhibition. In line with this, Liu et al. showed that UGCG 349 suppression restores apoptosis mediated by p53 in mutant p53 cancer cells (Liu et al., 2011). 350 However, MCF-7 cells exhibit the most increased aCDase mRNA expression as well as 351 increased proliferation. This fits the finding of Lucki et al. showing aCDase driven increased 352 proliferation of MCF-7 cells (Lucki and Sewer, 2011). Usually, aCDase overexpression in 353 breast cancer patients correlates with a better prognosis (Ruckhaberle et al., 2009, Sanger et 354 al., 2015).

355 Overall, levels of anabolic enzyme mRNA expression are more distinct than the mRNA levels 356 of catabolic enzymes in the analyzed cell lines. Increased anabolic sphingolipid enzyme 357 mRNA expression levels are indicated by an increase in total ceramide, sphingadiene358 ceramide, GalCer/GlcCer and SM levels in SKBr3 cells. Each sample contained the same cell 359 number, but SKBr3 cells are larger in size than T47D and MCF-7 cells. We assumed that the 360 total metabolite concentration might correlate with cell size and therefore differences in cell 361 size are compensated by normalization with MPR (Muschet et al., 2016). Normalization with 362 one IS per lipid class cannot compensate for unequal cell size, but often improves 363 measurement deviations. The volcano plots show that the differences between lipid levels 
364 are not ascribable to cell size, whereas the proliferation differs between the cell lines.

365 However, since dhCer levels are decreased and ceramide levels strongly increased in $\mathrm{SKBr} 3$

366 cells, it is likely that the dihydroceramide desaturase 1 (DES1) activity is elevated.

367 Interestingly, SKBr3 cells exhibit strongly increased sphingadiene-ceramide concentration.

368 Information about the biological function of sphingadiene-ceramides is limited.

369 Sphingadiene-ceramides inhibit the phosphoinositide 3-kinase (PI3K)/Akt and Wnt signaling

370 pathway leading to apoptosis (reviewed in (Hannun, 2015)).

371 Furthermore, we observed similar sphingolipid and non-sphingolipid expression patterns in

$372 \mathrm{SKBr} 3$ cells indicating a co-regulation of these lipid species. Especially, ether lipids are

373 strongly increased in SKBr3 cells, which is reversible by treatment with G15, a GPER1

374 antagonist. This is confirmed by strongly increased AGPS (generation of ether lipids) mRNA

375 expression (Summary Figure). Interestingly, it is shown that aggressive cancer cells exhibit

376 increased AGPS expression and ether lipid metabolism (Benjamin et al., 2013). Furthermore,

377 Chen et al. postulated that plasma ether-linked phosphocholine (PC) species can be used as a

378 biomarker for the diagnosis of breast cancer (Chen et al., 2016). One limitation of the study

379 from Chen et al. is the lack of information about the ER and GPER1 status of the breast

380 cancer. Our results do not confirm a general induction of ether lipid concentration in breast

381 cancer cells, but indicate a GPER1-dependent regulation. Since SKBr3 cells are a non-

382 aggressive cell line, GPER1-dependent increase of ether lipid synthesis does not state

383 aggressiveness of breast cancer cells in general. However, AGPS is located in the peroxisome

384 and is the rate-limiting enzyme in ether lipid synthesis (reviewed in (Dean and Lodhi, 2018)).

385 Surprisingly, GNPAT, which is also located in the peroxisome and essential for ether lipid

386 synthesis is only compared to MCF-7 cells significantly increased in SKBr3 cells. The reason

387 for this could be the finding that GNPAT enzyme activity does not only require AGPS

388 presence, but also depends on the integrity of channeling the substrate from GNPAT to

389 AGPS, which is shown by Itzkovitz et al. (Itzkovitz et al., 2012). Therefore, GNPAT activity

390 could be increased in SKBr3 cells leading to increased ether lipid synthesis without an

391 increased GNPAT mRNA level. Phosphocholine (PC)-ether species could not be detected in

392 T47D cells, but T47D cells exhibit a similar GNPAT mRNA expression as SKBr3 cells. GNPAT

393 does not contribute to ether lipid production in T47D cells. Either GNPAT is less active in

394 T47D cells or is expressed, because the enzyme also executes other tasks in T47D cells.

395 AGMO, an ether lipid cleaving enzyme, also exhibits strongly increased mRNA levels in SKBr3 
cells. This indicates that SKBr3 cells exhibit an accelerated ether lipid metabolism (Summary

397 Figure). A crosstalk between ether lipids and sphingolipids has been shown in

398 pathophysiological processes such as cancer and atopic dermatitis (reviewed in (Jimenez-

399 Rojo and Riezman, 2019)). GlcCer levels in cancer have been shown to correlate to ether

400 lipids through mechanisms that are linked to mammalian target of rapamycin (mTOR)

401 signaling, which is activated in most tumors (Guri et al., 2017). Therefore, previous studies

402 confirm our data showing that high ether lipid levels correlate with GSL levels in SKBr3 cells.

403 Ether lipids can be covalently attached to proteins as components of

404 glycosylphosphatidylinositol (GPI)-anchors. GPI-anchored proteins are linked to the

405 membrane in the ER via the hydrophobic part of the glycolipid and are mostly delivered to

406 the cell surface to execute diverse functions (reviewed in (Jimenez-Rojo and Riezman,

407 2019)). Typically GPI-anchored proteins are enriched in membrane microdomains (rafts) and

408 these microdomains exhibit high sphingolipid and cholesterol levels (reviewed in (Kinoshita,

409 2016)). In addition to increased ether lipid concentration, SKBr3 cells exhibit elevated

410 cholesterol levels. This indicates either increased raft formation or changed lipid

411 composition of rafts as compared to the other cell lines. Ether lipids also affect membrane

412 fluidity and cellular processes such as membrane fusion (reviewed in (Dean and Lodhi,

413 2018)). However, SKBr3 cells exhibit elevated DG levels. One possible mechanism leading to

414 increased DG levels is GPER1-dependent phospholipase C activation, which results in DG

415 production (reviewed in (Newton et al., 2016)). DGs function as second messengers in the

416 cell by activating protein kinase C (PKC) and PKC function in the cell is manifold (reviewed in

417 (Newton, 2018)). Interestingly, TG are the lowest in MCF-7 cells. Lofterød et al. showed that

418 increased TG levels are connected to promoted tumor growth (Lofterod et al., 2018), which

419 underlines the finding that SKBr3 cells have poor tumorigenic potential. Another interesting

420 finding is the low CPT1A mRNA level in SKBr3 cells, which follows the same trend as total

421 acylcarnitine level. Following production by CPT1A acylcarnitine is imported into

422 mitochondria and used for $\beta$-oxidation in form of acyl-CoA (reviewed in (Schooneman et al.,

423 2013)). The $\beta$-oxidation products nicotinamide adenine dinucleotide (NADH) and reduced

424 flavin adenine dinucleotide $\left(\mathrm{FADH}_{2}\right)$ are oxidized at the oxidative phosphorylation (OXPHOS)

425 complexes I and II. This generates the mitochondrial membrane potential, which is essential

426 for proper mitochondrial respiration function. The data indicate that SKBr3 cells execute less

427 B-oxidation, which might lead to reduced mitochondrial respiration. We have shown that 
428 GPER1 overexpression in MCF-7 cells leads to decreased basal respiration and reduced 429 glycolysis rate resulting in reduced cell proliferation (Wegner et al., 2019). However, acyl430 CoA needed for ether lipid synthesis could be generated by increased de novo lipogenesis.

\section{Conclusion}

432 In conclusion, the results of our semi-targeted analysis show co-regulation of sphingolipids 433 and non-sphingolipids in breast cancer cells with differing ER and GERP1 status. Especially, 434 GPER1 seems to influence expression of sphingolipids and ether lipids. Importantly, this co435 regulation might lead to a less tumorigenic potential. This finding might contribute to 436 identification of novel potential therapeutic targets in breast cancer treatment.

\section{Acknowledgements}

438 This work was funded by the Deutsche Forschungsgemeinschaft (WE 5825/1-1 and WE $4395825 / 2-1)$, the August Scheidel-Stiftung, the Heinrich und Fritz Riese-Stiftung, Johanna 440 Quandt-Jubiläumsfond and the Paul und Ursula Klein-Stiftung. Support by the SFB 1039 is 441 also gratefully acknowledged. The authors thank Ellen M. Olzomer for the linguistic revision 442 of the manuscript.

\section{Competing Interests}

444 We declare that the authors have no competing interests that might be perceived to influence the content of this manuscript.

\section{Author approvals}

447 All authors have seen and approved the manuscript. Furthermore, we ensure that the 448 manuscript hasn't been accepted or published elsewhere.

Figure 1: Estrogen receptor (ER) and G-protein coupled estrogen receptor 1 (GPER1) status and mRNA expression analysis of sphingolipid metabolizing enzymes in breast cancer cells by qRT-PCR. A ER $\alpha, E R \beta$ and GPER1 mRNA expression related to the housekeeping gene RPL37A. Data are presented as a mean of $n=3-8 \pm$ standard error of the mean (SEM). Tukey's

454 multiple comparison test. ${ }^{* * *} p \leq 0.0001$. B Heatmap of anabolic sphingolipid metabolizing 455 enzyme mRNA expression. mRNA expression is related to the housekeeping gene RPL37A. 
457 in white. Data are presented as a mean of $n=3$. Ceramide synthase $X$ (CerS $\mathrm{X}$ ), sphingosine 458 kinase 1 (SPHK1), sphingomyelin synthase 1 and 2 (SMS1 and 2), ceramide kinase 1 (CERK), 459 galactosylceramide synthase (GalCerS), UDP-glucose ceramide glucosyltransferase (UGCG). C 460 Heatmap of catabolic sphingolipid metabolizing enzyme mRNA expression. mRNA expression 461 is related to the housekeeping gene RPL37A. High values are represented as black, middle 462 range values are red and low values are shown in white. Data are presented as a mean of $463 n=3$. Acid ceramidase (aCDase), acid sphingomyelinase (aSMase), neutral sphingomyelinase $464 \quad 1,2$ and 3 (nSMase 1, 2 and 3).

465 Figure 2: Sphingolipid species in breast cancer cells identified by LC-HRMS analysis. A Total 466 dihydroceramide (dhCer) levels. Total of the following analytes: Cer d18:0/22:0, Cer 467 d18:0/24:0, Cer d18:0/24:1. B Total ceramide levels. Total of the following analytes: Cer $468 \mathrm{~d} 18: 1 / 16: 0$, Cer d18:1/18:0, Cer d18:1/22:0, Cer d18:1/22:1, Cer d18:1/23:0, Cer d18:1/24:0, 469 Cer d18:1/24:1. C Total sphingadiene-ceramide levels. Total of the following analytes: Cer $470 \mathrm{~d} 18: 2 / 22: 0$, Cer d18:2/24:0. D Total galactosy/ceramide (GalCer)/glucosylceramide (GlcCer) 471 levels. Total of the following analytes: HexCer d18:1/16:0, 24:0, 24:1. E Total 472 lactosylceramide (LacCer) levels. Total of the following analytes: Hex2Cer d18:1/16:0, 24:1. F 473 Total sphingomyelin (SM) levels. Total of the following analytes: SM 30:1, 32:1, 32:2, 33:1, $47434: 0,34: 1,34: 2,36: 1,36: 2,36: 3,37: 1,38: 1,38: 2,40: 1,40: 2,40: 3,41: 1,41: 2,42: 1,42: 2$, $47542: 3,43: 1,43: 2$. The identified single analytes are displayed in a heatmap in supplemental 476 data 1. Data are presented as a mean of $n=3 \pm$ SEM. Tukey's multiple comparison test. $477{ }^{*} p \leq 0.05,{ }^{* *} p \leq 0.01, * * * p \leq 0.001, * * * * p \leq 0.0001$. Area under curve (AUC), internal standard 478 (IS), not significant (ns).

Figure 3: Non-sphingolipid species in breast cancer cells identified by LC-HRMS analysis. A 480 Cholesterol (ST 27:1_OH). B Total sterol ester levels. Total of the following analytes: SE $48127: 1 / 14: 1,16: 1,17: 1,18: 1,18: 2,20: 3,20: 4,22: 6,24: 1$. C Total ether lipid levels. Total of the 482 following analytes: LPC 0-16:0, 16:1, 18:0, 18:1, PC 0-16:0_16:0, 18:2, 20:4, PC 0-16:1_16:0, 483 18:1, 18:2, 20:4, PC 0-18:1_20:4, PC 0-34:1, PE 0-16:1_18:2, 20:4, PE 0-18:1_18:1, 18:2, 484 20:4, LPE 0-16:1, 18:1. D Total diglyceride (DG) levels. Total of the following analytes: DG $48532: 1,32: 2,34: 1,34: 2,34: 3,36: 1,36: 2,36: 3,38: 2,38: 5$. E Total triglyceride (TG) levels. Total 486 of the following analytes: TG 42:1, 42:2, 43:0, 44:0, 44:1, 44:2, 46:0, 46:1, 46:2, 46:3, 48:0, $48748: 1,48: 2,48: 3,48: 4,50: 1,50: 2,50: 3,50: 4,52: 1,52: 2,52: 3,52: 4,52: 5,54: 1,54: 2,54: 3$, 
$54: 4,54: 5,54: 6,56: 1,56: 2,56: 3,56: 4,56: 6,58: 1,58: 2,58: 3,58: 4,58: 6$. F Total glycerophospholipids levels. Total of the following analytes: PE 32:1, 34:1, 34:2, 34:3, 36:1, $36: 2,36: 3,36: 4,36: 5,38: 4,38: 5,38: 6,40: 6,40: 7$, PG 34:1, 36:2, PI 32:1, 34:1, 34:2, 36:1, $36: 2,36: 4,38: 4,38: 6,40: 5,40: 6$, PS 32:1, 34:1, 34:2, 36:1, 36:2, 38:2, 38:3, PC 30:0, 30:1, $30: 2,32: 0,32: 1,32: 2,33: 2,34: 0,34: 1,34: 2,34: 3,34: 4,34: 5,36: 1,36: 2,36: 3,36: 4,36: 5$, $38: 2,38: 3,38: 4,38: 6,38: 7,40: 6,40: 7$. G Total lyso-glycerophospholipid levels. Total of the following analytes: LPE 16:0, 18:0, LPG 16:0, 18:1, 18:2, LPI 16:0, 18:0, 18:2, 20:3, 20:4, LPS 18:0, 18:1, LPC 14:0, 15:0, 16:0, 17:0, 18:0, 18:3, 20:0, 20:1, 20:3, 22:0, 24:0. H Total acylcarnitine levels. Total of the following analytes: acylcarnitine 14:1, 16:0, 18:0, 18:1. The identified single analytes are displayed in heatmaps in supplemental data 2. Data are presented as a mean of $n=3 \pm$ SEM. Tukey's multiple comparison test. ${ }^{*} p \leq 0.05,{ }^{* *} p \leq 0.01$, $* * * p \leq 0.001, * * * * p \leq 0.0001$. Area under curve (AUC), internal standard (IS), not significant 500 (ns).

501

502

503

504

505

506

507

508

509

510

511

512

513

514

515

516

517

518

Figure 4: Morphology, proliferation and ether lipid metabolizing enzyme mRNA expression analysis by qRT-PCR of MCF-7, T47D and SKBr3 cells. A Light microscopy images of breast cancer cells with differing ER and GPER1 status. A representative image of each breast cancer cell line is displayed. B Living cell number on day 1, 2, 3, 4 and 5. Data are presented as a mean of $n=3 \pm$ SEM. Tukey's multiple comparison test. C Glyceronephosphate Oacyltransferase (GNPAT), alkylglycerone phosphate synthase (AGPS), alkylglycerol monooxygenase (AGMO), fatty acid desaturase 1 (FADS1) and carnitine palmitoyltransferase $1 A(C P T 1 A)$ mRNA expression related to the housekeeping gene RPL37A. Data are presented as a mean of $n=3 \pm$ SEM. Tukey's multiple comparison test. ${ }^{*} p \leq 0.05,{ }^{* *} p \leq 0.01,{ }^{* *} p \leq 0.001$, $* * * * \leq 0.0001$.

Figure 5: Internal Standard (IS) normalized LC-HRMS data (upper row) and median peak ration (MPR) normalized LC-HRMS data (lower row). A SKBr3/MCF-7. B T47D/MCF-7. C $\mathrm{SKBr} 3 / \mathrm{T} 47 \mathrm{D}$.

Summary Figure: Summary of ether lipid metabolism alterations in GPER1 +, but ER - cells.

The acyl CoA required for ether lipid synthesis in SKBr3 cells might be generated by de novo lipogenesis rather than $\beta$-oxidation. Both key enzymes of ether lipid synthesis (glyceronephosphate O-acyltransferase (GNPAT) and alkylglycerone phosphate synthase (AGPS)) are strongly increased in SKBr3 cells. Since ether lipid degrading alkylglycerol 
bioRxiv preprint doi: https://doi.org/10.1101/2020.07.20.212894; this version posted July 21, 2020. The copyright holder for this preprint (which

was not certified by peer review) is the author/funder, who has granted bioRxiv a license to display the preprint in perpetuity. It is made available under aCC-BY-NC-ND 4.0 International license.

519 monooxygenase (AGMO) is also increased, accelerated ether lipid metabolism in GPER1 +

520 (ER -) cells is assumed (red arrow = displays changes in mRNA expression level).

521

522

523

524

525

526

527

528

529

530

531

532

533

534

535

536

537

538

539

540

541

542

543

544

545

546

547

548

549

550

551

552

553

554

555

556

557

558

559

560

561

562

563

564

565

566

\section{References}

ARANA, L., GANGOITI, P., OURO, A., TRUEBA, M. \& GOMEZ-MUNOZ, A. 2010. Ceramide and ceramide 1-phosphate in health and disease. Lipids Health Dis, 9, 15.

BENJAMIN, D. I., COZZO, A., JI, X., ROBERTS, L. S., LOUIE, S. M., MULVIHILL, M. M., LUO, K. \& NOMURA, D. K. 2013. Ether lipid generating enzyme AGPS alters the balance of structural and signaling lipids to fuel cancer pathogenicity. Proc Natl Acad Sci U S A, 110, 14912-7.

CHEN, M. \& HUANG, J. 2019. The expanded role of fatty acid metabolism in cancer: new aspects and targets. Precis Clin Med, 2, 183-191.

CHEN, X., CHEN, H., DAI, M., Al, J., LI, Y., MAHON, B., DAI, S. \& DENG, Y. 2016. Plasma lipidomics profiling identified lipid biomarkers in distinguishing early-stage breast cancer from benign lesions. Oncotarget, 7, 36622-36631.

CHU, K. C. \& ANDERSON, W. F. 2002. Rates for breast cancer characteristics by estrogen and progesterone receptor status in the major racial/ethnic groups. Breast Cancer Res Treat, 74, 199-211.

DEAN, J. M. \& LODHI, I. J. 2018. Structural and functional roles of ether lipids. Protein Cell, 9, 196206.

DEI CAS, M. \& GHIDONI, R. 2018. Cancer Prevention and Therapy with Polyphenols: SphingolipidMediated Mechanisms. Nutrients, 10.

DENG, Y., MIKI, Y. \& NAKANISHI, A. 2020. Estradiol/GPER affects the integrity of mammary duct-like structures in vitro. Sci Rep, 10, 1386.

FURUYA, H., SHIMIZU, Y. \& KAWAMORI, T. 2011. Sphingolipids in cancer. Cancer Metastasis Rev, 30, 567-76.

GARUFI, A., PISTRITTO, G., CIRONE, M. \& D'ORAZI, G. 2016. Reactivation of mutant p53 by capsaicin, the major constituent of peppers. J Exp Clin Cancer Res, 35, 136.

GURI, Y., COLOMBI, M., DAZERT, E., HINDUPUR, S. K., ROSZIK, J., MOES, S., JENOE, P., HEIM, M. H., RIEZMAN, I., RIEZMAN, H. \& HALL, M. N. 2017. mTORC2 Promotes Tumorigenesis via Lipid Synthesis. Cancer Cell, 32, 807-823.e12.

HAHNEFELD, L., GURKE, R., THOMAS, D., SCHREIBER, Y., SCHAFER, S. M. G., TRAUTMANN, S., SNODGRASS, I. F., KRATZ, D., GEISSLINGER, G. \& FERREIROS, N. 2020. Implementation of lipidomics in clinical routine: Can fluoride/citrate blood sampling tubes improve preanalytical stability? Talanta, 209, 120593.

HANNUN, Y. A. L., C.; MAO, C.; OBEID, L.M 2015. Bioactive Sphingolipids in Cancer Biology and Therapy, Springer.

HSU, L. H., CHU, N. M., LIN, Y. F. \& KAO, S. H. 2019. G-Protein Coupled Estrogen Receptor in Breast Cancer. Int J Mol Sci, 20.

ITZKOVITZ, B., JIRALERSPONG, S., NIMMO, G., LOSCALZO, M., HOROVITZ, D. D., SNOWDEN, A., MOSER, A., STEINBERG, S. \& BRAVERMAN, N. 2012. Functional characterization of novel mutations in GNPAT and AGPS, causing rhizomelic chondrodysplasia punctata (RCDP) types 2 and 3. Hum Mutat, 33, 189-97.

JIMENEZ-ROJO, N. \& RIEZMAN, H. 2019. On the road to unraveling the molecular functions of ether lipids. FEBS Lett, 593, 2378-2389.

KINOSHITA, T. 2016. Glycosylphosphatidylinositol (GPI) Anchors: Biochemistry and Cell Biology: Introduction to a Thematic Review Series. J Lipid Res, 57, 4-5.

LIM, J. Y. K., H. Y. 2018. Roles of Lipids in Cancer. Lipid Metabolism IntechOpen.

LIM, L. Y., VIDNOVIC, N., ELLISEN, L. W. \& LEONG, C. O. 2009. Mutant p53 mediates survival of breast cancer cells. Br J Cancer, 101, 1606-12. 
LIU, Y. Y., PATWARDHAN, G. A., BHINGE, K., GUPTA, V., GU, X. \& JAZWINSKI, S. M. 2011. Suppression of glucosylceramide synthase restores $p 53$-dependent apoptosis in mutant $\mathrm{p} 53$ cancer cells. Cancer Res, 71, 2276-85.

LOFTEROD, T., MORTENSEN, E. S., NALWOGA, H., WILSGAARD, T., FRYDENBERG, H., RISBERG, T., EGGEN, A. E., MCTIERNAN, A., AZIZ, S., WIST, E. A., STENSVOLD, A., REITAN, J. B., AKSLEN, L. A. \& THUNE, I. 2018. Impact of pre-diagnostic triglycerides and HDL-cholesterol on breast cancer recurrence and survival by breast cancer subtypes. BMC Cancer, 18, 654.

LONG, J., ZHANG, C. J., ZHU, N., DU, K., YIN, Y. F., TAN, X., LIAO, D. F. \& QIN, L. 2018. Lipid metabolism and carcinogenesis, cancer development. Am J Cancer Res, 8, 778-791.

LUCKI, N. C. \& SEWER, M. B. 2011. Genistein stimulates MCF-7 breast cancer cell growth by inducing acid ceramidase (ASAH1) gene expression. J Biol Chem, 286, 19399-409.

MALTSEVA, D. V., KHAUSTOVA, N. A., FedotoV, N. N., MATVEeVA, E. O., LeBedeV, A. E., SHKURNIKOV, M. U., GALATENKO, V. V., SCHUMACHER, U. \& TONEVITSKY, A. G. 2013. Highthroughput identification of reference genes for research and clinical RT-qPCR analysis of breast cancer samples. J Clin Bioinforma, 3, 13.

MORO, K., KAWAGUCHI, T., TSUCHIDA, J., GABRIEL, E., QI, Q., YAN, L., WAKAI, T., TAKABE, K. \& NAGAHASHI, M. 2018. Ceramide species are elevated in human breast cancer and are associated with less aggressiveness. Oncotarget, 9, 19874-19890.

MOTA, A. L., EVANGELISTA, A. F., MACEDO, T., OLIVEIRA, R., SCAPULATEMPO-NETO, C., VIEIRA, R. A. \& MARQUES, M. M. C. 2017. Molecular characterization of breast cancer cell lines by clinical immunohistochemical markers. Oncol Lett, 13, 4708-4712.

MUSCHET, C., MOLLER, G., PREHN, C., DE ANGELIS, M. H., ADAMSKI, J. \& TOKARZ, J. 2016. Removing the bottlenecks of cell culture metabolomics: fast normalization procedure, correlation of metabolites to cell number, and impact of the cell harvesting method. Metabolomics, 12, 151.

NAGAHASHI, M., TSUCHIDA, J., MORO, K., HASEGAWA, M., TATSUDA, K., WOELFEL, I. A., TAKABE, K. \& WAKAl, T. 2016. High levels of sphingolipids in human breast cancer. J Surg Res, 204, 435444.

NELSON, M. E., LAHIRI, S., CHOW, J. D., BYRNE, F. L., HARGETT, S. R., BREEN, D. S., OLZOMER, E. M., WU, L. E., COONEY, G. J., TURNER, N., JAMES, D. E., SLACK-DAVIS, J. K., LACKNER, C., CALDWELL, S. H. \& HOEHN, K. L. 2017. Inhibition of hepatic lipogenesis enhances liver tumorigenesis by increasing antioxidant defence and promoting cell survival. Nat Commun, 8 , 14689.

NEWTON, A. C. 2018. Protein kinase C: perfectly balanced. Crit Rev Biochem Mol Biol, 53, 208-230.

NEWTON, A. C., BOOTMAN, M. D. \& SCOTT, J. D. 2016. Second Messengers. Cold Spring Harb Perspect Biol, 8.

OLDE, B. \& LEEB-LUNDBERG, L. M. 2009. GPR30/GPER1: searching for a role in estrogen physiology. Trends Endocrinol Metab, 20, 409-16.

OWCZAREK, T. B., SUCHANSKI, J., PULA, B., KMIECIK, A. M., CHADALSKI, M., JETHON, A., DZIEGIEL, P. \& UGORSKI, M. 2013. Galactosylceramide affects tumorigenic and metastatic properties of breast cancer cells as an anti-apoptotic molecule. PLoS One, 8, e84191.

PAKIET, A., KOBIELA, J., STEPNOWSKI, P., SLEDZINSKI, T. \& MIKA, A. 2019. Changes in lipids composition and metabolism in colorectal cancer: a review. Lipids Health Dis, 18, 29.

PFISTER, C., TATABIGA, M. S. \& ROSER, F. 2011. Selection of suitable reference genes for quantitative real-time polymerase chain reaction in human meningiomas and arachnoidea. BMC Res Notes, 4, 275.

PUJOL, P., HILSENBECK, S. G., CHAMNESS, G. C. \& ELLEDGE, R. M. 1994. Rising levels of estrogen receptor in breast cancer over 2 decades. Cancer, 74, 1601-6.

RUCKHABERLE, E., HOLTRICH, U., ENGELS, K., HANKER, L., GATJE, R., METZLER, D., KARN, T., KAUFMANN, M. \& RODY, A. 2009. Acid ceramidase 1 expression correlates with a better prognosis in ER-positive breast cancer. Climacteric, 12, 502-13. 
618

RYLAND, L. K., FOX, T. E., LIU, X., LOUGHRAN, T. P. \& KESTER, M. 2011. Dysregulation of sphingolipid metabolism in cancer. Cancer Biol Ther, 11, 138-49.

SANGER, N., RUCKHABERLE, E., GYORFFY, B., ENGELS, K., HEINRICH, T., FEHM, T., GRAF, A., HOLTRICH, U., BECKER, S. \& KARN, T. 2015. Acid ceramidase is associated with an improved prognosis in both DCIS and invasive breast cancer. Mol Oncol, 9, 58-67.

SCHOMEL, N., HANCOCK, S. E., GRUBER, L., OLZOMER, E. M., BYRNE, F. L., SHAH, D., HOEHN, K. L., TURNER, N., GROSCH, S., GEISSLINGER, G. \& WEGNER, M. S. 2019. UGCG influences glutamine metabolism of breast cancer cells. Sci Rep, 9, 15665.

SCHOONEMAN, M. G., VAZ, F. M., HOUTEN, S. M. \& SOETERS, M. R. 2013. Acylcarnitines: reflecting or inflicting insulin resistance? Diabetes, 62, 1-8.

SUKOCHEVA, O. \& WADHAM, C. 2014. Role of sphingolipids in oestrogen signalling in breast cancer cells: an update. J Endocrinol, 220, R25-35.

SUKOCHEVA, O., WADHAM, C., HOLMES, A., ALBANESE, N., VERRIER, E., FENG, F., BERNAL, A., DERIAN, C. K., ULLRICH, A., VADAS, M. A. \& XIA, P. 2006. Estrogen transactivates EGFR via the sphingosine 1-phosphate receptor Edg-3: the role of sphingosine kinase-1. J Cell Biol, 173, 301-10.

TORRE, L. A., SIEGEL, R. L., WARD, E. M. \& JEMAL, A. 2016. Global Cancer Incidence and Mortality Rates and Trends--An Update. Cancer Epidemiol Biomarkers Prev, 25, 16-27.

WANG, D., HU, L., ZHANG, G., ZHANG, L. \& CHEN, C. 2010. G protein-coupled receptor 30 in tumor development. Endocrine, 38, 29-37.

WEGNER, M. S., GRUBER, L., SCHOMEL, N., TRAUTMANN, S., BRACHTENDORF, S., FUHRMANN, D., SCHREIBER, Y., OLESCH, C., BRUNE, B., GEISSLINGER, G. \& GROSCH, S. 2019. GPER1 influences cellular homeostasis and cytostatic drug resistance via influencing long chain ceramide synthesis in breast cancer cells. Int J Biochem Cell Biol, 112, 95-106.

WEGNER, M. S., SCHIFFMANN, S., PARNHAM, M. J., GEISSLINGER, G. \& GROSCH, S. 2016. The enigma of ceramide synthase regulation in mammalian cells. Prog Lipid Res, 63, 93-119.

WEGNER, M. S., WANGER, R. A., OERTEL, S., BRACHTENDORF, S., HARTMANN, D., SCHIFFMANN, S., MARSCHALEK, R., SCHREIBER, Y., FERREIROS, N., GEISSLINGER, G. \& GROSCH, S. 2014. Ceramide synthases CerS4 and CerS5 are upregulated by 17beta-estradiol and GPER1 via AP1 in human breast cancer cells. Biochem Pharmacol, 92, 577-89.

WESIERSKA-GADEK, J., SCHREINER, T., MAURER, M., WARINGER, A. \& RANFTLER, C. 2007. Phenol red in the culture medium strongly affects the susceptibility of human MCF-7 cells to roscovitine. Cell Mol Biol Lett, 12, 280-93. 


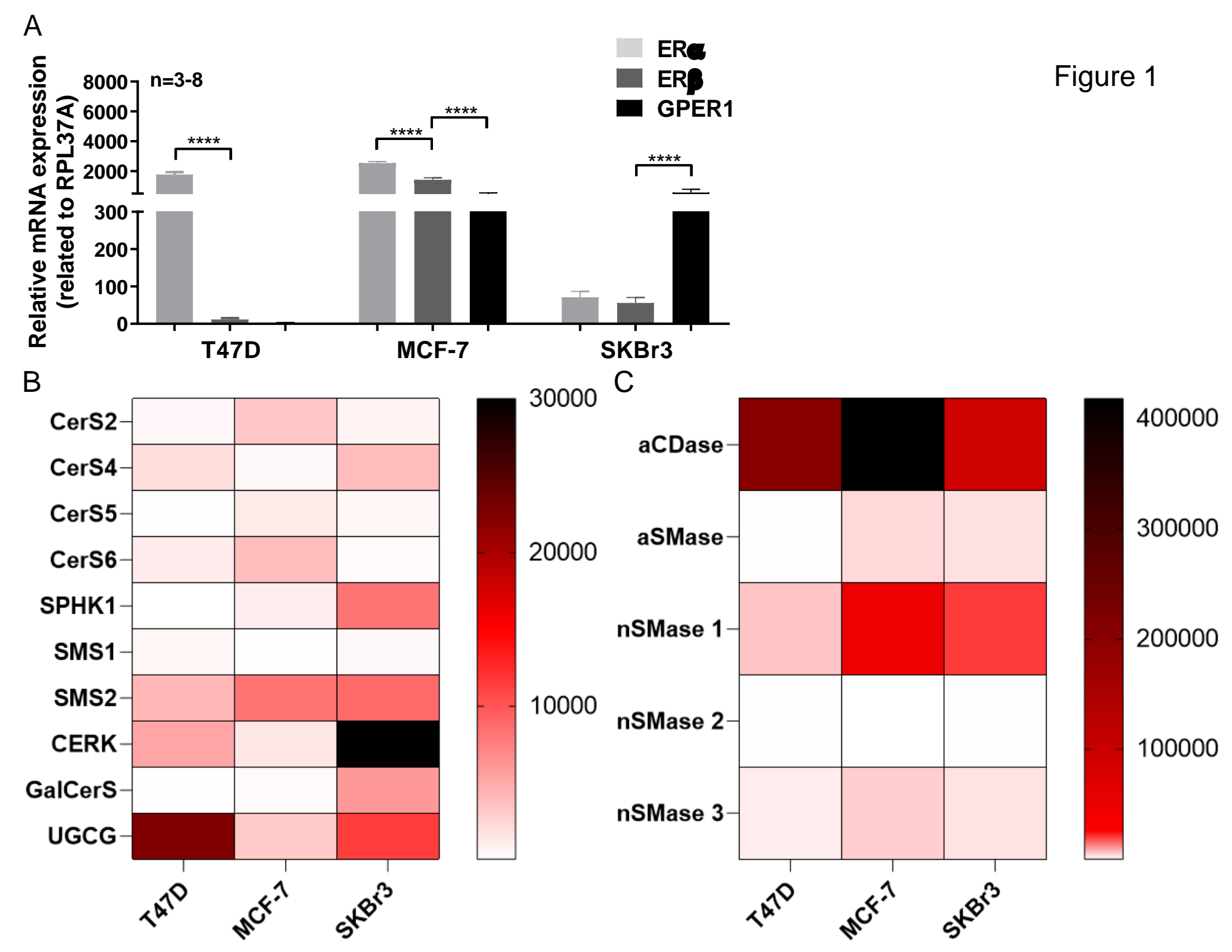



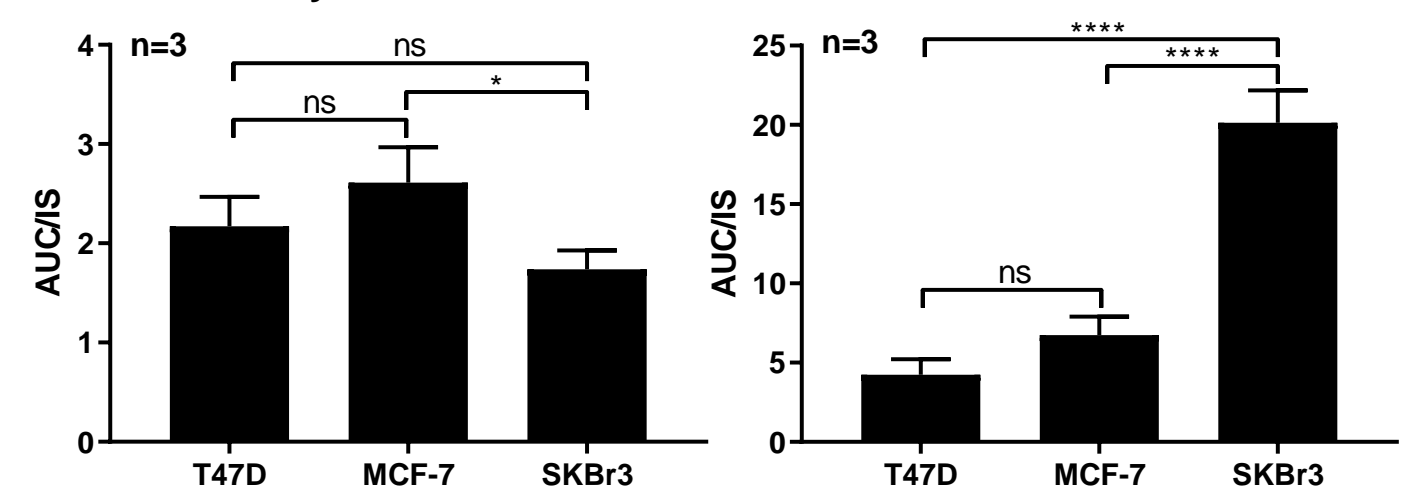

C

sphingadiene-ceramide

$D$ galactosylceramide/glucosylceramide
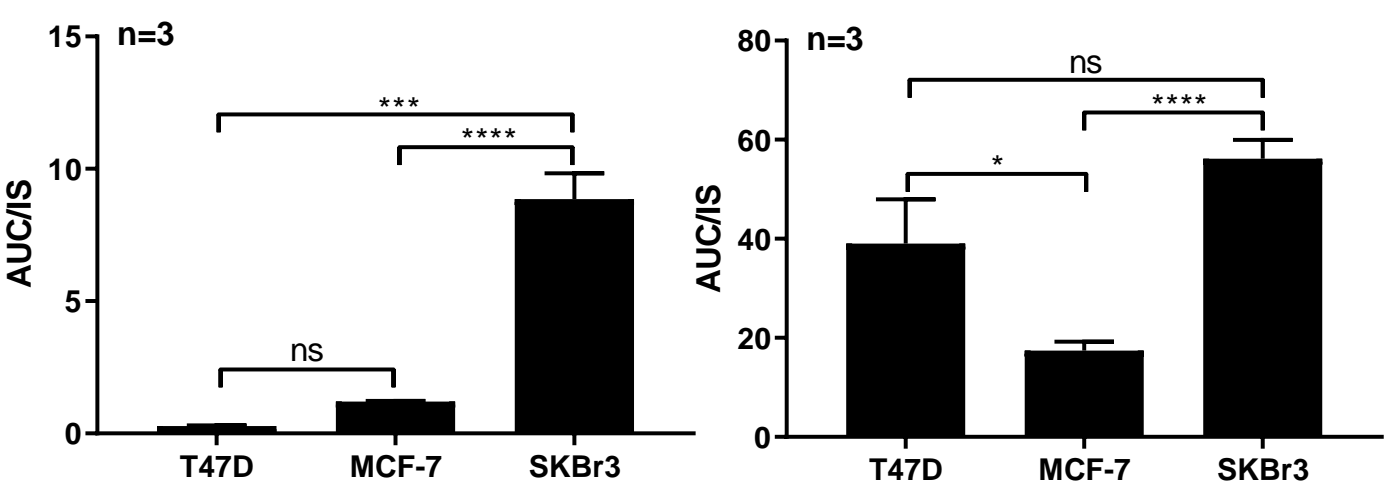

E

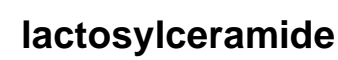

F

sphingomyelin
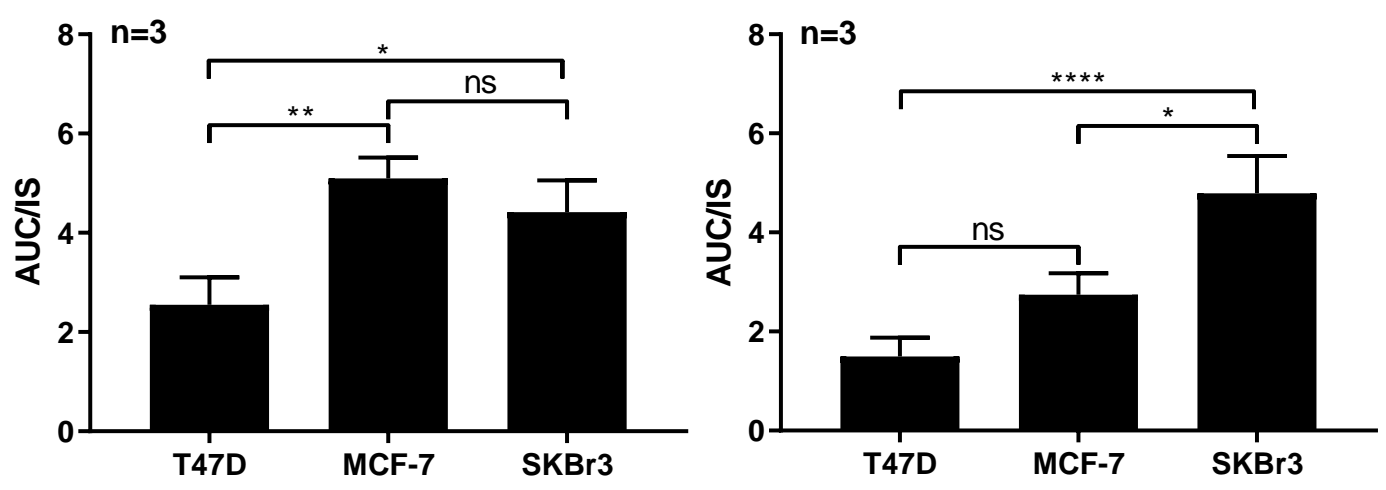

Figure 2 
$A$

cholesterol

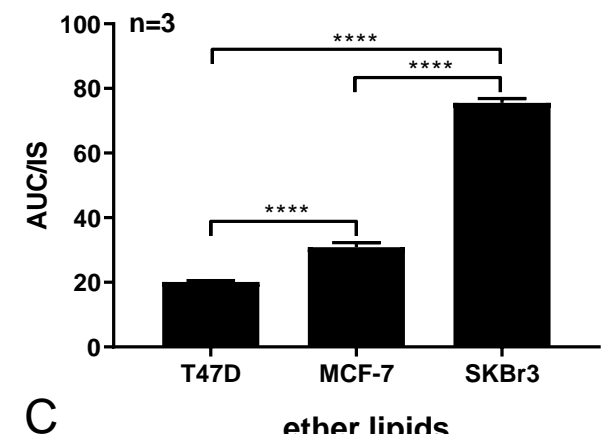

C
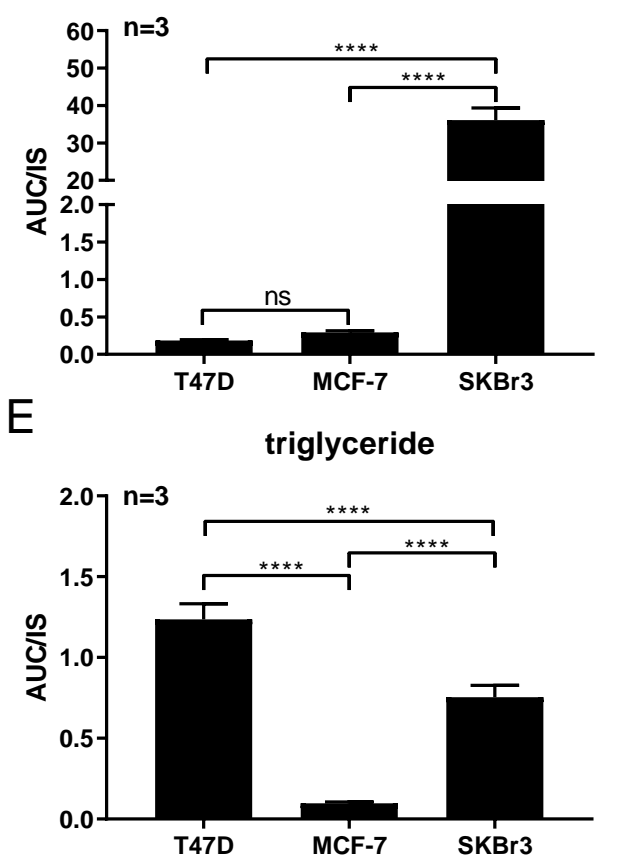

G

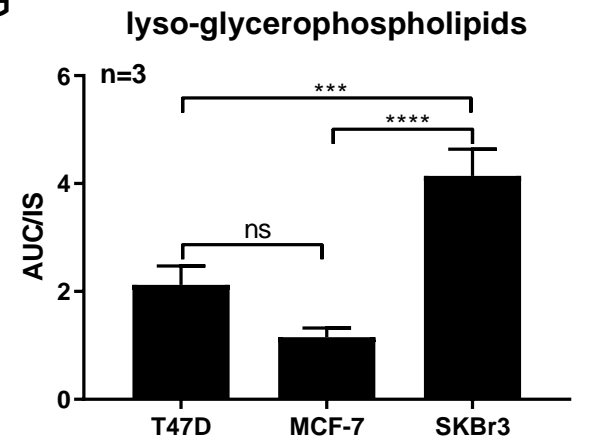

B sterol ester
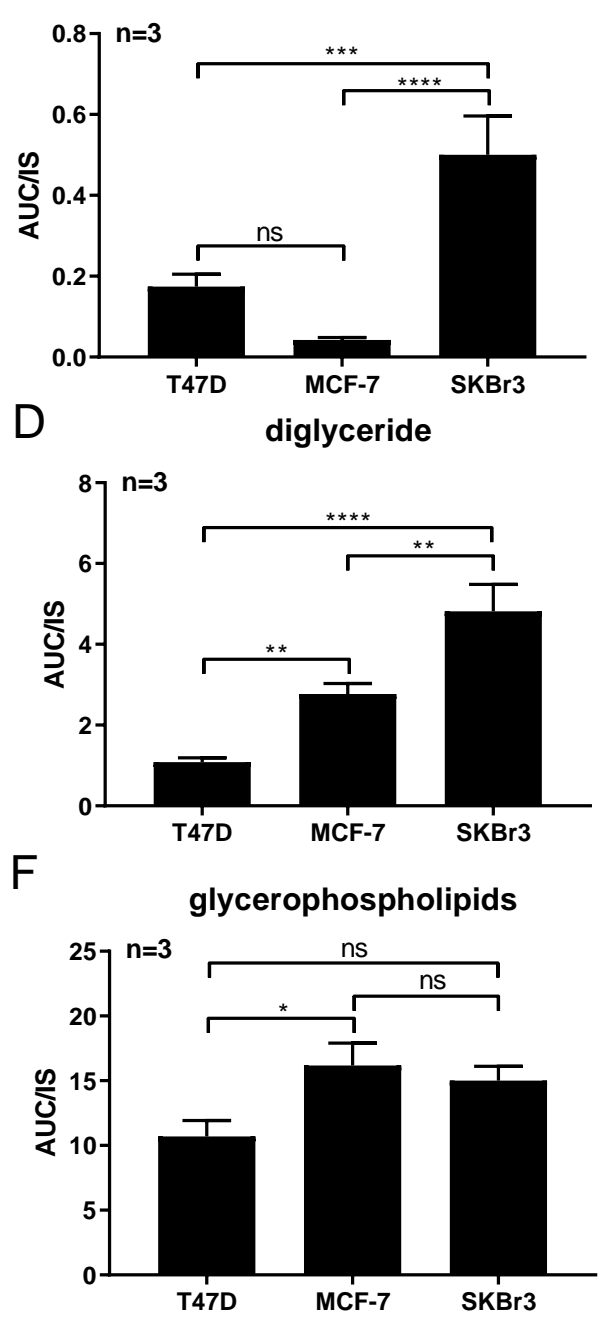

$\mathrm{H}$

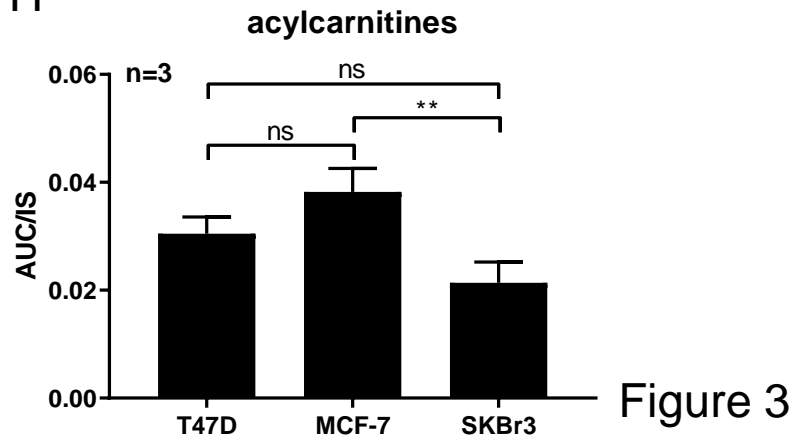



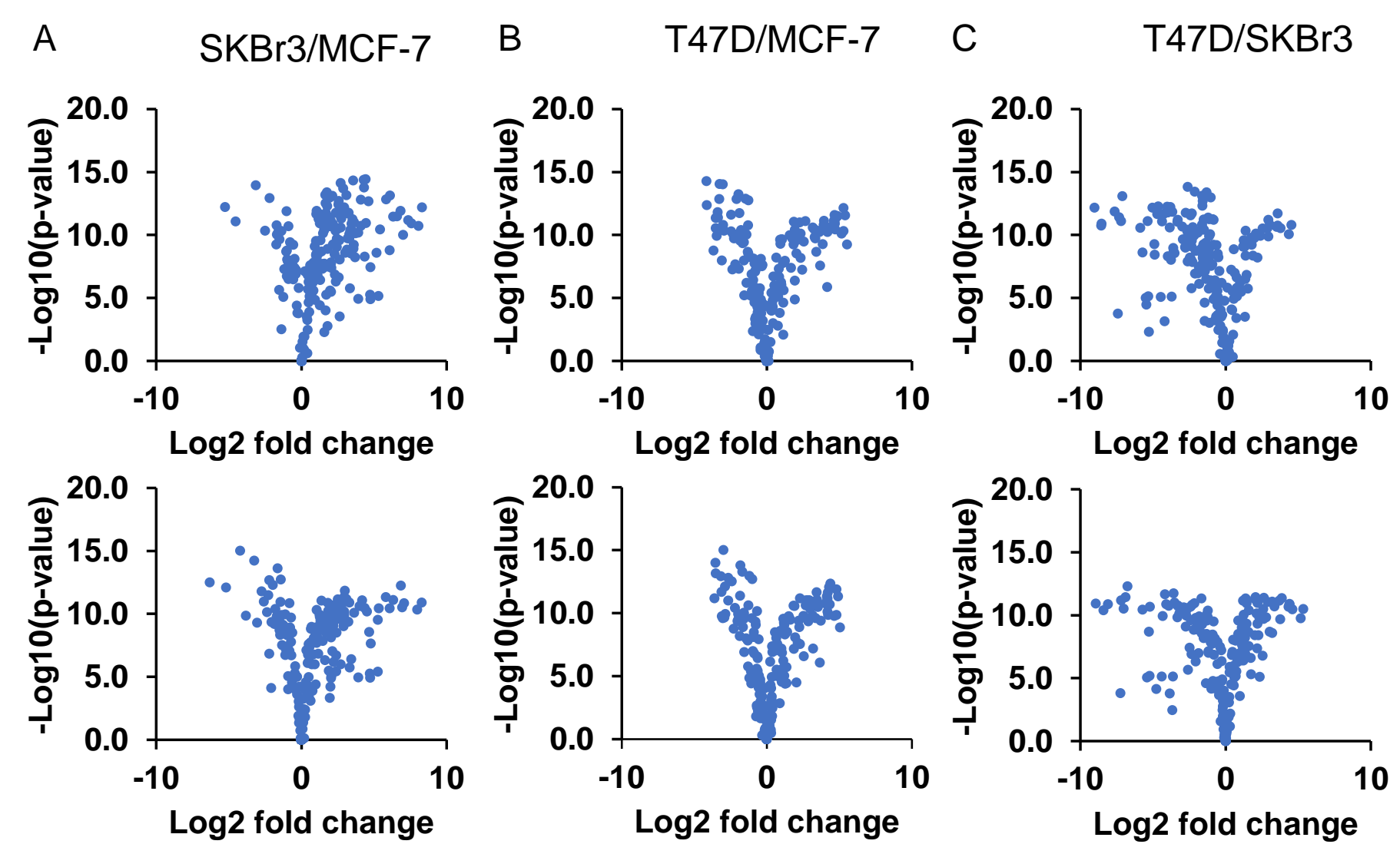

Figure 5 


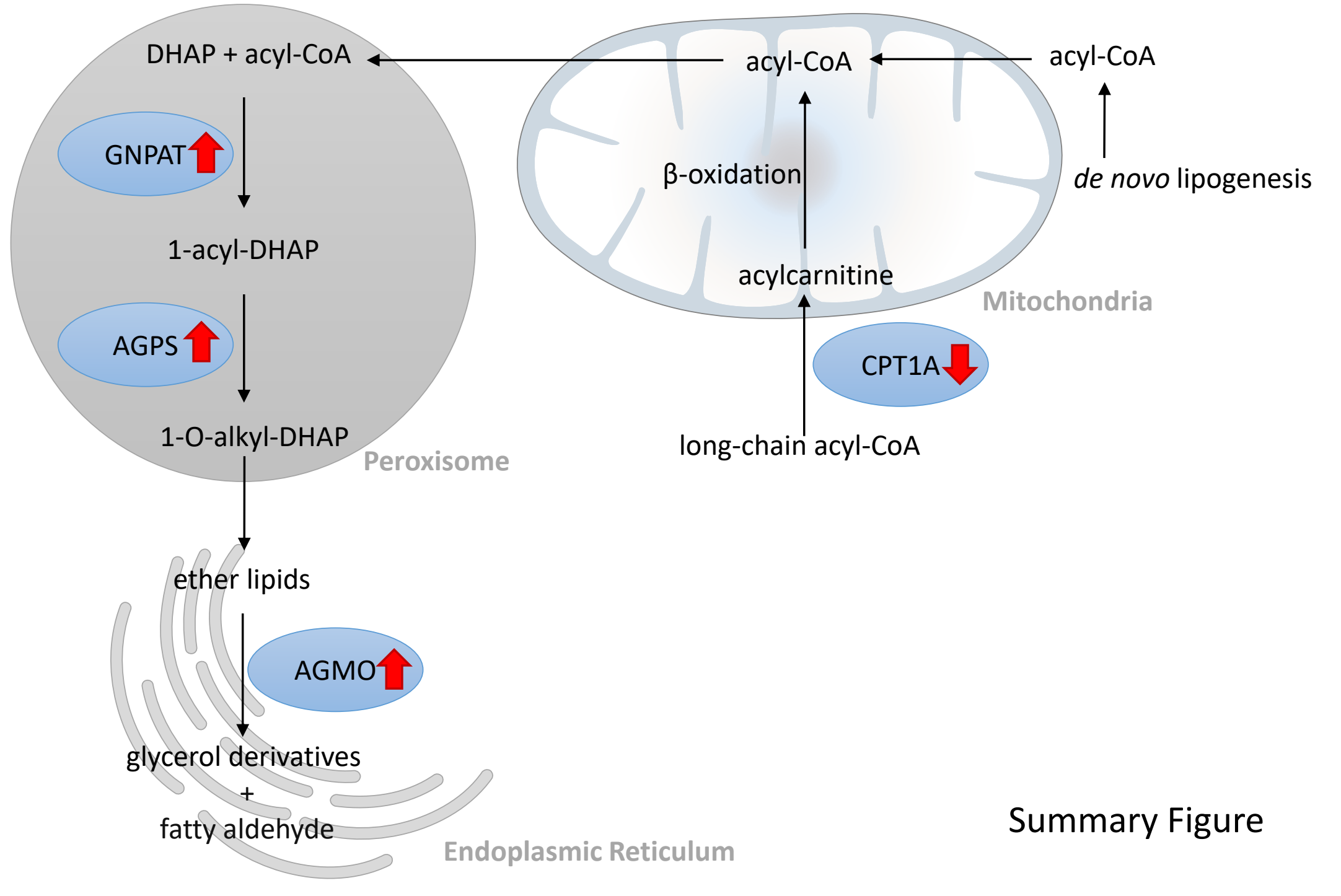

